Leiden-Boston: Brill, 2012.296 pages ill

\title{
Isabel Yaya. The Two Faces of Inca History. Dualism in the Narratives and Cosmology of Ancient Cuzco
}

\section{Arnaud Ansart}

\section{(2) OpenEdition}

Journals

Édition électronique

URL : http://journals.openedition.org/bifea/5293

DOI : $10.4000 /$ bifea.5293

ISSN : 2076-5827

Éditeur

Institut Français d'Études Andines

Édition imprimée

Date de publication : 1 août 2014

Pagination : 369-372

ISSN : 0303-7495

Référence électronique

Arnaud Ansart, "Isabel Yaya. The Two Faces of Inca History. Dualism in the Narratives and Cosmology of Ancient Cuzco », Bulletin de l'Institut français d'études andines [En ligne], 43 (2) | 2014, mis en ligne le 08 août 2014, consulté le 06 novembre 2020. URL : http://journals.openedition.org/bifea/5293 ; DOI : https://doi.org/10.4000/bifea.5293

\section{(c)}

Les contenus du Bulletin de l'Institut français d'études andines sont mis à disposition selon les termes de la licence Creative Commons Attribution - Pas d'Utilisation Commerciale - Pas de Modification 4.0 International. 


\section{Reseñas}

\section{Isabel Yaya. The Two Faces of Inca History. Dualism in the Narratives and Cosmology of Ancient Cuzco. Leiden-Boston: Brill, 2012. 296 p. ill.}

Bien qu'il aborde un sujet déjà traité à plusieurs reprises depuis des décennies, le livre The Two Faces of Inca History: Dualism in the Narratives and Cosmology of Ancient Cuzco d'Isabel Yaya propose une approche innovante du dualisme dans la société inca qui mérite de ne pas passer inaperçu des spécialistes et ni des néophytes.

Cette approche pluridisciplinaire issue de l'anthropologie historique et dans une moindre mesure de la philologie se fonde sur des prémisses dérivées du principe dumontien des relations hiérarchiques, développé plus tard par Terence Turner sur le terrain des sociétés du Brésil central. Elle part de l'idée que les oppositions binaires, sociales ou symboliques, sont nécessairement hiérarchiques et n'ont pas nécessairement tendance à converger vers une relation symétrique. Toute organisation dualiste fondée sur une base segmentaire implique donc un système social fondamentalement inégal.

L'auteure applique cette approche à trois aspects de la société inca : les représentations des oppositions de moitiés dans les narrations historiques et les rituels incas, les conceptions cosmologiques de l'élite dirigeante et enfin, son calendrier cérémoniel. Elle articule son ouvrage en deux parties équilibrées. La première analyse les productions historiques que l'élite dirigeante inca mit en place pour asseoir sa légitimité et expliquer le succès de son expansion. Cette partie se divise en trois chapitres. Le chapitre 1 examine les différents supports de transmission historique que les Incas utilisèrent (ex. khipus, tablones etc.), mais s'interroge également sur le contexte d'énonciation dans lequel ces récits s'inscrivaient. L'auteure discute ensuite comment les conventions littéraires des

* El Bulletin de l'Institut Français d'Études Andines no se responsabiliza por las opiniones vertidas en esta sección. 
colons européens influencèrent la transcription de ces traditions. Le chapitre 2 analyse la façon dont les relations dualistes antagoniques étaient dépeintes dans les traditions historiques incas d'une part, et comment elles étaient refondues en action rituelle de l'autre. L'auteure identifie alors les principes hiérarchiques sous-jacents aux relations de parenté au sein de l'élite dirigeante et pose comme principe que le modèle du clan conique ne clarifie pas seulement les normes de reproduction du groupe de descendance, mais explique aussi les mécanismes sociaux à l'origine des guerres de succession et des conflits entre lignages royaux. De la sorte, elle met en évidence l'existence de deux types de discours incas, certes concurrents, mais qui légitimaient par différents moyens discursifs l'accession au pouvoir des dirigeants dont la mémoire a été conservée. Le chapitre 3 reprend la démarche d'analyse du chapitre précédent et l'étend aux relations entre l'élite inca et les seigneurs de provinces, en mettant l'accent sur les fêtes métropolitaines, notamment sitwa et qhapaq hucha, qui impliquaient la participation de célébrants étrangers et pour lesquelles des relations asymétriques étaient établies.

La seconde partie de l'ouvrage réexamine la cosmologie inca et enquête sur la façon dont les fêtes instaurées par l'État ont régi le quotidien de l'élite gouvernementale de Cuzco. Tout d'abord, à travers l'exemple de deux récits fondateurs de la dynastie royale relatant les actes mythiques de Wiraqucha (chapitre 4) et de P'unchaw (chapitre 5), Isabel Yaya montre que chacun de ces récits dépeint une cosmologie dominée par des divinités distinctes mais néanmoins complémentaires. Ces entités se seraient relayées au cours de l'année pour réguler le cycle de l'eau dont la bonne circulation depuis la mer souterraine jusqu'au cosmos assurait la vitalité des êtres. Ces traditions se divisaient en deux groupes mutuellement contradictoires qui chacun offrait une représentation particulière du passé mythique. A la lumière des principes dualistes, ces deux chapitres tentent de rendre compte des incohérences qui ont obscurci les récits espagnols au sujet de la religion inca et enquêtent sur les paradigmes indigènes qui ont facilité la fusion de Wiraqucha avec le Dieu de la chrétienté. Enfin, dans le chapitre 6, I'auteure redessine une image du calendrier annuel à partir des caractéristiques qu'elle identifie pour chaque division saisonnière du cycle cérémoniel et à partir de données archéo-astronomiques. Elle propose un cycle divisé en deux périodes quasi équivalentes, chacune régie par un aspect différent du dieu Soleil.

En tant qu'archéologue, l'apport théorique et méthodologique de cet ouvrage me semble important car la société inca apparaît ici sous un jour nouveau. En examinant cette société au travers du principe dualiste asymétrique, les éléments déclencheurs des conflits inter-lignagers et des guerres de succession trouvent ici leur explication. Surtout, il apparaît clairement que l'Inca régnant fonde son " gouvernement» non pas sur un noyau dur de principes immuables, mais sur un système protéiforme absorbant tout élément susceptible de lui être utile ; ce qui en a fait inévitablement sa force mais aussi son " talon d'Achille » pour citer l'auteure. Hormis ces nouveaux aspects qu'il révèle sur la société inca, l'ouvrage d'Isabel Yaya, écrit dans un style fluide et soucieux de clarifier chaque détail, a deux mérites. Tout d'abord, les concepts et le système de pensée de la société 
étudiée, celle des Incas, sont ici interrogés par une approche émique qui aborde les incohérences des sources historiques non pas seulement comme des élaborations coloniales, mais également comme le fait d'une tradition historique composite antérieure à l'arrivée des espagnols. Ensuite, le fait que l'auteure aboutisse à de telles conclusions en ré-analysant des sources de première main montre que ces documents pourtant maintes fois étudiés depuis des décennies n'ont pas encore révélé tous leurs secrets.

Au-delà de ce nouveau regard sur le fonctionnement de la société inca, ce travail incite à de nouvelles réflexions quant à l'étude archéologique des cultures andines préhispaniques. Au premier tournant du XXe siècle, au Pérou, plusieurs archéologues issus d'institutions diverses comme Max Uhle ou Rafael Larco Hoyle mettent au jour des vestiges matériels en majorité céramique, jusqu'alors inconnus des scientifiques. Dans les décennies qui voient l'apparition de ces découvertes, les théories de Kustav Kossinna (1920 : 3) sont dominantes et ce, même si elles comportaient plusieurs failles méthodologiques identifiées (Eggers, 1950). Faute de comparaisons ethno-historiques possibles, ces chercheurs s'emparent de l'axiome du célèbre archéologue allemand pour qui « des provinces culturelles nettement délimitées coïncident à toutes les époques avec des peuples ou avec des tribus bien précis ». Ils rattachent donc la multiplicité des styles céramiques mis au jour à autant de «cultures », puis à des ethnies de même nom. Tous les autres vestiges, comme les tombes et leurs contenus, les objets en métal, bois ou pierre, ou les monuments se retrouvent par ce glissement sémantique regroupés de facto dans des ensembles « stylistico-culturels » définis par les céramiques. Ainsi apparaissent pour la côte sud du Pérou, les cultures Paracas, Topará et Nasca entre autre, qui selon les théories évolutionnistes en vigueur, apparaissent puis disparaissent pour céder la place à la suivante. Malgré les découvertes successives qui remettent sans cesse en cause ces théories, les chercheurs actuels continuent d'employer cette classification superficielle des « cultures» soit par commodité soit parce qu'il leur est devenu difficile de s'en détacher. Or, désormais les archéologues andinistes se retrouvent malgré eux à appliquer les termes « culture matérielle, identité culturelle, ethnie/ethnicité » devenus de véritables « fourre-tout sémantique » aux différents ensembles de vestiges identifiés (Kaulicke, 2009). Le cas Virú-Gallinazo/ Mochica (IIle s av. - IXe s ap. J.-C.) de la côte nord du Pérou illustre bien cette situation confuse : les deux termes ont d'abord désignés deux styles céramiques, puis deux cultures distinctes, puis deux ethnies vivant au sein d'une même culture désignée parfois comme une seule et même société. Aujourd'hui ces termes désignent des cultures matérielles (alias phénomènes culturels) qui renvoient à deux classes sociales distinctes (Uceda et al., 2009). Mais au final, quelle que soit la définition retenue, les ensembles archéologiques (ou cultures matérielles) définis par les premiers archéologues sont toujours considérés et étudiés comme des entités distinctes.

Déjà remise en cause plusieurs fois par les découvertes archéologiques, cette vision simpliste et monolithique des «cultures» du monde andin vole encore une fois en éclat à la lumière de l'analyse minutieuse qu'Isabel Yaya entreprend 
de la société inca. L'auteure démontre que l'élite dirigeante de Cuzco n'était pas monolithique mais volontairement protéiforme. Désormais il faut admettre que le cour de l'élite inca ne se reproduisait pas immuablement de manière endogame mais qu'il était bien la résultante de prises de pouvoir « illégitimes », d'échanges entre les membres des maisons nobles et les chefs locaux, et de dynamiques redéployées sans cesse par des processus étatiques multiples, en premier lieu les rituels. Cette analyse appliquée aux autres sociétés préhispaniques rend caduque toute tentative archéologique d'identification ethnique à partir des seules données matérielles disponibles, surtout quand l'étude de celles-ci se concentre majoritairement sur la céramique !

Pour autant l'appréhension des transitions culturelles n'est pas condamnée, bien au contraire. En effet, puisque dans le cas des Incas, les changements institutionnels ont été simultanés des changements d'autorité divine (chapitres 4 et 5), ces bouleversements se seraient répercutés notamment dans l'organisation des rituels et des espaces cérémoniels dans lesquels est inscrite la sociologie des participants. II conviendrait alors d'orienter davantage nos recherches sur I'analyse spatiale, perceptuelle et symbolique des centres cérémoniels, ces études ne représentant à ce jour qu'à peine $10 \%$ des données pour les cultures pré-incas du Pérou. Conjuguée à l'étude iconographique des pratiques funéraires associées à ces structures, une telle méthodologie offrirait certainement des pistes interprétatives différentes de celles des changements de « cultures» (en fait des changements stylistico-culturels) par conflit ou par cohabitation pacifique.

\section{Références citées}

EGGERS, H. J., 1950 - Das Problem der ethnischen Deutung in der Frühgeschichte. In: Urund Frühgeschichte als historische Wissenschaft : Festschr (H. Kirchner, ed.): 49-59; Heidelberg.

KAULICKE, P., 2009 - Concluding Remarks. In: Gallinazo: an Early Cultural Tradition on the Peruvian North Coast (J.-F. Millaire \& M. Morlion, eds.): 233-242; Los Ángeles: Cotsen Institute of Archaeology Press.

KOSSINNA, K., 1920 - Die Herkunft der Germanen. Zur Methode der Siedlungsarchäologie, 80 pp.; Leipzig.

UCEDA, S., GAYOSO, H. \& GAMARRA, N., 2009 - Lo Gallinazo en Moche, iestilo o cultura? In: Gallinazo: an Early Cultural Tradition on the Peruvian North Coast (J.-F. Millaire \& M. Morlion, eds.): 105-124; Los Ángeles: Cotsen Institute of Archaeology Press. 